\title{
Serum Procalcitonin as a Biomarker in Complicated Appendicitis - A Cross Sectional Study
}

\author{
Sreeramulu Patrapalli Nadipanna ${ }^{1}$, Shashidhar Kurpad Nagaraj², Varsha Anand ${ }^{3}$ \\ ${ }^{1}$ Department of General Surgery, Sri Devaraj Urs Medical College Institute of Sri Devaraj Urs Academy of \\ Higher Education and Research, Kolar, Karnataka, India. ${ }^{2}$ Department of Biochemistry, Sri Devaraj Urs \\ Medical College Institute of Sri Devaraj Urs Academy of Higher Education and Research, Kolar, \\ Karnataka, India. ${ }^{3}$ Department of General Surgery, Sri Devaraj Urs Medical College Institute of Sri \\ Devaraj Urs Academy of Higher Education and Research, Kolar, Karnataka, India.
}

\section{ABSTRACT}

\section{BACKGROUND}

Early diagnosis and treatment of acute appendicitis prevents development of markers that have been used to improve the diagnostic accuracy in appendicitis. The objective of this study was to assess the role of procalcitonin in the prediction of complications of appendicitis.

\section{METHODS}

A cross sectional study involving 110 patients diagnosed with acute appendicitis was conducted. After obtaining ethical clearance, informed written consent was obtained from the patients. Blood investigations such as total leucocyte counts, $\mathrm{C}$ reactive proteins and procalcitonin levels were done. Cases were categorized into uncomplicated appendicitis $(n=67)$ and complicated appendicitis $(n=43)$. Descriptive analysis, ROC analysis of predictive validity, and Shapiro Wilk test comparing all the three parameters in both the groups was done using IBM SPSS version 22.

\section{RESULTS}

The mean age was $29.59 \pm 9.17$ years. $67(60.91 \%)$ had uncomplicated appendicitis and 43 (39.09\%) had complicated appendicitis. The WBC, hsCRP, serum procalcitonin percentile had good predictive validity in predicting score as indicated by the area under the curve $(0.822)$. Serum procalcitonin value had a sensitivity of $97.67 \%$ in predicting the type of appendicitis and specificity of $94.03 \%$.

\section{CONCLUSIONS}

Serum procalcitonin is a better biomarker than total leucocyte count and hs-C reactive protein in predicting complications of appendicitis and differentiating it from uncomplicated appendicitis.

\section{KEY WORDS}

Procalcitonin, Predictor, Complicated Appendicitis
Corresponding Author: Dr. Shashidhar Kurpad Nagaraj, Sri Devaraj Urs Medical College Institute of Sri Devaraj Urs Academy of Higher Education and Research, Kolar, Karnataka, India.

E-mail: drshashik1971@yahoo.co.in

DOI: $10.14260 /$ jemds/2020/464

How to Cite This Article: Nadipanna SP, Nagaraj SK, Anand V. Serum procalcitonin as a biomarker in complicated appendicitis - a cross sectional study. J. Evolution Med. Dent. Sci. 2020;9(30):2129-2132, $10.14260 /$ jemds/2020/464

Submission 15-04-2020,

Peer Review 14-06-2020,

Acceptance 22-06-2020,

Published 27-07-2020.

Copyright (C) 2020 JEMDS. This is an open access article distributed under Creative Commons Attribution License [Attribution 4.0 International (CC BY 4.0)] 


\section{BACKGROUND}

Acute appendicitis is the most common surgical emergency in the world and appendectomy is the most common surgery performed worldwide. ${ }^{1}$ It mostly occurs in young patients with almost $40 \%$ of the cases occurring in the age group of 10 and 29 years. ${ }^{2}$ Rate of perforation, postoperative morbidity, mortality and prolonged hospital stay can be curtailed by early diagnosis and treatment. The average rate of perforation at presentation varies between $16 \%$ and $30 \%$ and any delay in diagnosis further increases the rate of development of complications. ${ }^{3}$

Though sophisticated imaging and laboratory modalities are available for early diagnosis, clinical examination findings remain the common method employed for diagnosis and early therapeutic interventions. The accuracy of diagnosing using clinical method is sometimes questionable as it can lead to false positive or false negative diagnosis.

As an adjuvant to the clinical examination, several laboratory parameters such as estimation of total leucocyte count (TLC), C reactive protein (HS-CRP) and procalcitonin (PCT) have been used to improve the accuracy of clinical diagnosis of Acute appendicitis. ${ }^{4}$

Procalcitonin (PCT) is a prohormone of calcitonin it is a 110 amino acid protein produced by the parafollicular $\mathrm{C}$ cells of thyroid and Kulchitsky cells of the lung. It is raised in cases presenting with clinically significant bacterial infections, sepsis but not raised in case of sterile inflammation or viral infection. ${ }^{5}$ Whereas HS-CRP is raised in all the inflammatory conditions irrespective of it being sterile or infected and total leucocyte counts can increase in any stressful conditions. ${ }^{6}$

Procalcitonin degrades to catacalcin-calcitonin and residual protein with a half-life of about 25-30 hours. This allows timely repeated measurements that may reflect changes of the underlying clinical condition. Bacterial lipopolysaccharides and the proinflammatory cytokines are the most potent inducers of PCT release. It has been demonstrated that the injection of bacterial endotoxin into healthy subjects causes an increase in PCT by $0.5 \mathrm{ng} / \mathrm{mL}$ per hour after a latency of about 2-3 hours and reaching a plateau after 6-12 hours. $^{7}$

As a result, PCT cannot only be reliable biomarker to diagnose acute complicated appendicitis but other such inflammatory conditions like pneumonia, pancreatitis. When coupled with clinical examination, diagnostic imaging PCT can serve as an invaluable biomarker to predict and monitor the outcome in complicated appendicitis. The normal levels of PCT are less than $0-0.05 \mathrm{ng} / \mathrm{mL}$, in cases with low risk of sepsis values ranges from $0.05-0.5 \mathrm{ng} / \mathrm{mL}$, moderate risk of sepsis values ranges from $0.5-2 \mathrm{ng} / \mathrm{mL}$ and in severe sepsis levels are more than $2 \mathrm{ng} / \mathrm{mL} .6,8$ Need for a simple yet effective marker to differentiate simple from complicated appendicitis has lead us to take up this study.

\section{Objectives}

1. To and compare the values of Total Leucocyte Count, Creactive protein and procalcitonin levels in Simple and Complicated Acute Appendicitis.

2. To assess the value of procalcitonin as a predictor of diagnosis and severity of acute appendicitis.

\section{METHODS}

Institutional Ethical Clearance and informed written consent was be taken before start of the study. This is a descriptive cross-sectional prospective study carried out one hundred and ten patients presenting with symptoms of acute appendicitis. Clinically diagnosed cases of pneumonia, pancreatitis, renal disease, thyroid disorders, urinary tract infections were excluded. Sample size was calculated by using the formula

$$
\left.n=\frac{[\operatorname{DEFF} * \mathrm{~Np}(1-\mathrm{p})]}{[(\mathrm{d} 2 / \mathrm{Z} 21-\alpha / 2 *(\mathrm{~N}-1)}+\mathrm{p} *(1-\mathrm{p})\right]
$$

These cases were later categorised as simple appendicitis $(n=67)$ and complicated appendicitis $(n=43)$. All the cases were later confirmed by histopathology.

\section{Methods of Data Collection}

Procalcitonin was measured using luminometric method (LUMI Test). Total Leucocyte count was estimated using SYSMEX Automated cell counter method. (Volumetric Impedance - Coulter method). hsCRP was based on the principle of enzyme-linked immunosorbent assay. Total leucocyte count was reconfirmed on peripheral blood smear examination. Patients name was not revealed and is identified only by the hospital number. Hence patient privacy and confidentiality was maintained.

\section{Statistical Methods}

All the values are entered into master chart. TLC, HS-CRP and serum procalcitonin were considered as primary outcome variables. Type of appendicitis was considered as Primary explanatory variable. Descriptive analysis was carried out by mean and standard deviation for quantitative variables, frequency and proportion for categorical variables. Nonnormally distributed quantitative variables were summarized by median and interquartile range (IQR). Data was also represented using appropriate diagrams like bar diagram, pie diagram and box plots. All Quantitative variables were checked for normal distribution within each category of explanatory variable by using visual inspection of histograms and normality Q-Q plots. Shapiro-Wilk test was also conducted to assess normal distribution. Shapiro Wilk test $p$ value of $>0.05$ was considered as normal distribution. $\mathrm{P}$ value $<0.05$ was considered statistically significant. IBM SPSS version 22 was used for statistical analysis. ${ }^{9}$

ROC analysis compares different variables i.e. CRP levels, TLC levels, and serum procalcitonin.

\section{RESULTS}

A total of 110 subjects were included in the final analysis. The mean age was $29.59 \pm 9.17$ years in the study population. Among the study population, 67 (60.91\%) were men and 43 (39.09\%) were female. Among the study population, 67 
(60.91\%) had uncomplicated appendicitis and 43 (39.09\%) had complicated appendicitis. All the details are represented in table 1. The mean TLC, HS-CRP, Serum procalcitonin was 10.31 (0.9 to 25 ), 2.89 (0.4 to 8.8) and 2.35 (0.0 to 22 ) in the study population. The comparison of all the three parameters are represented in table 2.

\begin{tabular}{|c|c|}
\hline Parameter & Summary \\
\hline Age (Mean \pm S.D.) & $29.59 \pm 9.17$ \\
\hline \multicolumn{2}{|c|}{ Gender } \\
\hline Male & $67(60.91 \%)$ \\
\hline Female & $43(39.09 \%)$ \\
\hline Type of Appendicitis & Frequency \\
\hline Appendicitis (Uncomplicated) & $67(60.91 \%)$ \\
\hline Complicated & $43(39.09 \%)$ \\
\hline \multicolumn{2}{|l|}{$\begin{array}{l}\text { Appendicitis with perforation }-30 / 43 \\
\text { Gangrenous appendicitis - } 13 / 43\end{array}$} \\
\hline Table 1. Summary of Base & istics $(n=110)$ \\
\hline
\end{tabular}

\begin{tabular}{|c|c|c|c|}
\hline \multirow{2}{*}{ Parameter } & \multicolumn{2}{|c|}{ Type of Appendicitis } & \multirow{2}{*}{ P Value } \\
\hline & Uncomplicated $(n=67)$ & Simple $(n=43)$ & \\
\hline $\begin{array}{l}\text { TLC }(\text { Mean } \pm \text { SD) - } \\
\text { cells/cumm }\end{array}$ & $8.56 \pm 2.63$ & $13.04 \pm 4.96$ & $<0.001$ \\
\hline $\begin{array}{l}\text { HS-CRP (Median (IQR)) - } \\
\text { mg/dl }\end{array}$ & $\begin{array}{c}2.1 \\
(1.5,2.4)\end{array}$ & $\begin{array}{c}3.4 \\
(2.5,5.6)\end{array}$ & $<0.001$ \\
\hline $\begin{array}{l}\text { Serum Procalcitonin- } \mathrm{ng} / \mathrm{mL} \\
\text { (Median (IQR)) }\end{array}$ & $\begin{array}{c}0.13 \\
(0.05,0.4)\end{array}$ & $4.83(1.85,7.94)$ & $<0.001$ \\
\hline \multicolumn{4}{|c|}{ Table 2. Comparison of Lab Parameters between } \\
\hline
\end{tabular}

\begin{tabular}{|c|c|c|c|c|}
\hline \multirow{2}{*}{ Parameters } & \multirow{2}{*}{$\begin{array}{l}\text { Area Under } \\
\text { the Curve }\end{array}$} & \multicolumn{2}{|c|}{ Asymptotic 95\% CI } & \multirow{2}{*}{ P Value } \\
\hline & & Lower & Upper & \\
\hline TLC & 0.822 & 0.731 & 0.914 & $<0.001$ \\
\hline HS-CRP & 0.818 & 0.731 & 0.905 & $<0.001$ \\
\hline $\begin{array}{c}\text { Serum } \\
\text { Procalcitonin }\end{array}$ & 0.959 & 0.913 & 1.000 & $<0.001$ \\
\hline \multicolumn{5}{|c|}{$\begin{array}{c}\text { Table 3. Predictive Value WBC, hs-CRP, and Serum Procalcitonin } \\
\text { Predicting Complicated Appendicitis }\end{array}$} \\
\hline
\end{tabular}

The TLC, HS-CRP, serum procalcitonin percentile had good predictive validity in predicting score as indicated by area under the curve of 0.822 (95\% CI 0.731 to 0.914 , p value $<0.001$ ), 0.818 (95\% CI 0.731 to 0.905 , p value $<0.001$ ) and 0.959 ( $95 \%$ CI 0.913 to 1.000 , $p$ value $<0.001$ ). (Figure $1 \mathrm{~A}, 1 \mathrm{~B}$, 1C).

\begin{tabular}{|c|c|c|c|}
\hline Parameters & $\begin{array}{c}\text { WBC } \\
(95 \% \mathrm{CI})\end{array}$ & $\begin{array}{l}\text { hs-CRP } \\
(95 \% \mathrm{CI})\end{array}$ & $\begin{array}{c}\text { Serum } \\
\text { Procalcitonin } \\
(95 \% \mathrm{CI})\end{array}$ \\
\hline Sensitivity & $\begin{array}{c}81.40 \% \\
(66.60 \%-91.61 \%)\end{array}$ & $\begin{array}{c}81.40 \% \\
(66.60 \%-91.61 \%)\end{array}$ & $\begin{array}{c}97.67 \% \\
(87.71 \%-99.94 \%)\end{array}$ \\
\hline Specificity & $\begin{array}{c}79.10 \% \\
(67.43 \%-88.08 \%)\end{array}$ & $\begin{array}{c}80.60 \% \\
(69.11 \%-89.24 \%)\end{array}$ & $\begin{array}{c}94.03 \% \\
(85.41 \%-98.35 \%)\end{array}$ \\
\hline False positive rate & $\begin{array}{c}20.90 \% \\
(11.92 \%-32.57 \%)\end{array}$ & $\begin{array}{c}19.40 \% \\
(10.76 \%-30.89 \%)\end{array}$ & $\begin{array}{c}5.97 \% \\
(1.65 \%-14.59 \%)\end{array}$ \\
\hline False negative rate & $\begin{array}{c}18.60 \% \\
(8.39 \%-33.40 \%)\end{array}$ & $\begin{array}{c}18.60 \% \\
(8.39 \%-33.40 \%)\end{array}$ & $\begin{array}{c}2.33 \% \\
(0.06 \%-12.29 \%)\end{array}$ \\
\hline $\begin{array}{c}\text { Positive predictive } \\
\text { value }\end{array}$ & $\begin{array}{c}71.43 \% \\
(56.74 \%-83.42 \%)\end{array}$ & $\begin{array}{c}72.92 \% \\
(58.15 \%-84.72 \%)\end{array}$ & $\begin{array}{c}91.30 \% \\
(79.21 \%-97.58 \%)\end{array}$ \\
\hline $\begin{array}{c}\text { Negative predictive } \\
\text { value }\end{array}$ & $\begin{array}{c}86.89 \% \\
(75.78 \%-94.16 \%)\end{array}$ & $\begin{array}{c}87.10 \% \\
(76.15 \%-94.26 \%)\end{array}$ & $\begin{array}{c}98.44 \% \\
(91.60 \%-99.96 \%)\end{array}$ \\
\hline Diagnostic accuracy & $\begin{array}{c}80.00 \% \\
(71.30 \%-87.02 \%)\end{array}$ & $\begin{array}{c}80.91 \% \\
(72.31 \%-87.78 \%)\end{array}$ & $\begin{array}{c}95.45 \% \\
(89.71 \%-98.51 \%)\end{array}$ \\
\hline \multicolumn{4}{|c|}{$\begin{array}{c}\text { Table 4. Predictive Validity of WBC in Predicting } \\
\text { Type of Appendicitis }(n=110)\end{array}$} \\
\hline
\end{tabular}

The WBC value had sensitivity of $81.40 \%$ (95\% CI 66.60\%$91.61 \%)$ in predicting type of appendicitis. Specificity was $79.10 \%$ (95\% CI $67.43 \%-88.08 \%$ ), false positive rate was $20.90 \%$ (95\% CI $11.92 \%-32.57 \%$ ), false negative rate was $18.60 \%$ (95\% CI $8.39 \%-33.40 \%$ ), positive predicting value was $71.43 \%$ (95\% CI 56.74\%-83.42\%), negative predictive value was $86.89 \%$ (95\% CI 75.78\%-94.16\%) and diagnostic accuracy was $80.00 \%$ (95\% CI 71.30\%-87.02\%). The HS-CRP value had sensitivity of $81.40 \%$ (95\% CI $66.60 \%-91.61 \%$ ) in predicting type of appendicitis. Specificity was $80.60 \%(95 \%$ CI $69.11 \%-89.24 \%$ ), false positive rate was $19.40 \%$ (95\% CI $10.76 \%-30.89 \%)$, false negative rate was $18.60 \%(95 \% \mathrm{CI}$ $8.39 \%-33.40 \%)$, positive predicting value was $72.92 \%(95 \%$ CI $58.15 \%-84.72 \%$ ), negative predictive value was $87.10 \%$ (95\% CI 76.15\%-94.26\%) and diagnostic accuracy was 80.91\% (95\% CI 72.31\%-87.78\%). The Serum procalcitonin value had sensitivity of $97.67 \%$ (95\% CI $87.71 \%-99.94 \%$ ) in predicting type of appendicitis. Specificity was $94.03 \%$ (95\% CI $85.41 \%-98.35 \%)$, false positive rate was 5.97\% (95\% CI $1.65 \%-14.59 \%)$, false negative rate was $2.33 \%(95 \% \mathrm{CI}$ $0.06 \%-12.29 \%)$, positive predicting value was $91.30 \%(95 \%$ CI 79.21\%-97.58\%), negative predictive value was $98.44 \%$ (95\% CI 91.60\%-99.96\%) and diagnostic accuracy was 95.45\% (95\% CI 89.71\%-98.51\%). (Table 3)

\section{DISCUSSION}

The lifetime risks of undergoing appendectomy for men are $12 \%$ and women are $25 \%$. In spite of the availability of sophisticated diagnostic techniques like ultrasound and various laboratory advances, appendicitis has a $15 \%$ rate of misdiagnosis. ${ }^{10}$ These investigations have also number of other limitations like cost of the investigation, risk of exposure to radiation, need for an operator, risk of false positive or negative diagnosis and difficulty in diagnosing pregnant women and children. Hence, the need for an easy and costeffective method for diagnosing is present. The role of various inflammatory biomarkers had been explored in the past to aid in diagnosis of appendicitis. Low cost and moderate diagnostic accuracy markers such as total leucocyte counts, high cost and high accuracy markers such as pro-calcitonin, IL 6 and urinary 5-HIAA has been described. Acharya A, Markar SR, Ni M, Hanna GB. Biomarkers of acute appendicitis: systematic review and cost-benefit trade-off analysis. Surg Endosc 2017; 31:10221031. DOI 10.1007/s00464-016-5109.

However, the reports in this regard are conflicting. A study in India among children showed that procalcitonin was a better indicator for diagnosing acute appendicitis compared to HS-CRP and other markers. ${ }^{11}$ Another study had concluded that the diagnostic value of $\mathrm{D}$ dimer and procalcitonin are no better marker compared to HS-CRP. ${ }^{12}$ But in recent times the role of these biomarkers in differentiating complicated and uncomplicated appendicitis is being explored. The current study is an attempt to add to the existing evidence on role of procalcitonin in predicting complications of appendicitis among paediatric age group.

In the current study, $9.09 \%$ of the cases were complicated the most common complications were perforation $(17.27 \%)$, appendicitis with gangrene $(9.09 \%)$ and abscess with faecolith $(4.55 \%)$. This is similar to the findings of study where, $16 \%$ of the study participants presented with appendiceal perforation. ${ }^{13}$ Appendiceal rupture/ perforation is the most common complication worldwide, caused due to delay in diagnosing or seeking medical care. ${ }^{14}$

We have found the median value of procalcitonin to be significantly higher among the complicated appendicitis (4.83 
$\mathrm{ng} / \mathrm{dl})$ as compared to uncomplicated appendicitis $(0.13$ $\mathrm{ng} / \mathrm{dl}$ ). Median HS-CRP value for complicated appendicitis was 3.4 and in uncomplicated was 2.1. Mean WBC value in complicated appendicitis was 13.04 and in uncomplicated was 8.56. The difference observed between the complicated and uncomplicated values were statistically significant $(\mathrm{p}<0.001)$. A thorough literature search was done for finding the mean value differences between complicated and uncomplicated appendicitis, but no studies were found reporting mean values. A study among adults with appendicitis, procalcitonin levels above $0.5 \mathrm{ng} / \mathrm{mL}$ was observed among the study participants. ${ }^{15}$ The large fraction of patients with acute appendicitis who demonstrate a PCT increase in this study $(62 \%)$ was contradictory to study by another study in which only $14.3 \%$ of patients had PCT levels $>0.5 \mathrm{ng} / \mathrm{mL} .16$

This may be due to very early presentation of the patients to the emergency which doesn't allow the procalcitonin to reach significant levels.

Based on the findings of ROC analysis, the predictive validity of PCT as indicated by area under the curve was 0.959 which was statistically significant $(\mathrm{p}<0.001)$. The predictive validity of TLC was 0.822 and HS-CRP was 0.818 which were significantly lower as compared to PCT. The sensitivity and specificity of PCT in predicting appendicitis were $97.67 \%$ and $94.03 \%$ respectively. When compared to TLC $(81.40 \%$, $79.10 \%)$ and HS-CRP $(81.40 \%, 80.60 \%)$, PCT has high predictive accuracy. This is similar to a study done by where PCT had sensitivity of $44 \%$ and specificity of $100 \% .^{4}$ Similar study done in children showed that PCT value of $>0.5 \mathrm{ng} / \mathrm{mL}$ was found to be indicative of perforation or gangrene with $73.4 \%$ sensitivity and $94.6 \%$ specificity. ${ }^{17} \mathrm{~A}$ study also showed that the positive predictive value of PCT for abscess and/or perforation was higher than that of HS-CRP (73\% vs. 48\%) among their study patients. This is similar to the findings of the current study, where the positive predictive value of PCT in predicting complicated appendicitis was $91.30 \%$ which was higher than TLC and HS-CRP. 6 With pooled sensitivity of $62 \%$ and specificity of $94 \%$ our study shows that the procalcitonin level can be used as an predictor of complicated appendicitis.

\section{CONCLUSIONS}

Procalcitonin biomarker levels can be used as a predictor of complications of appendicitis. Clinical signs can be correlated with procalcitonin levels to diagnose complicated appendicitis early so that appropriate therapeutic decisions can be taken. Procalcitonin levels are elevated in infections and hence, it can be used as a predictor of postoperative infectious complications.

\section{Limitations}

This study was conducted on relatively young adult population; hence, generalizability to whole population is not possible. Also, the study was done on relatively small number of patients. The cost and methodology of measuring procalcitonin must also be kept in mind before taking any decisions.

\section{REFERENCES}

[1] Addiss DG, Shaffer N, Fowler BS, et al. The epidemiology of appendicitis and appendectomy in the United States. Am J Epidemiol 1990;132 (5):910-25.

[2] Humes D, Simpson J. Acute appendicitis. BMJ 2006;333 (7567):530-4.

[3] Bickell NA, Aufses AH, Rojas M, et al. How time affects the risk of rupture in appendicitis. J Am Coll Surg 2006;202 (3):401-6.

[4] Vaziri M, Ehsanipour F, Pazouki A, et al. Evaluation of procalcitonin as a biomarker of diagnosis, severity and postoperative complications in adult patients with acute appendicitis. Med J Islam Repub Iran. 2014;28:50.

[5] Le Moullec JM, Jullienne A, Chenais J, et al. The complete sequence of human preprocalcitonin. FEBS Lett 1984;167 (1):93-7.

[6] Yamashita H, Yuasa N, Takeuchi E, et al. Diagnostic value of procalcitonin for acute complicated appendicitis. Nagoya J Med Sci 2016;78 (1):79-88.

[7] Brunkhorst F, Heinz U, Forycki Z. Kinetics of procalcitonin in iatrogenic sepsis. Intensive Care Med 1998;24 (8):8889.

[8] Rajkumari N, Mathur P, Sharma S, et al. Procalcitonin as a predictor of sepsis and outcome in severe trauma patients: a prospective study. J Lab Physicians 2013;5 (2):100-8.

[9] IBM Corp. IBM SPSS statistics for windows. Version 22.0. Armonk, NY: IBM Corp 2013.

[10] Liang MK, Andersson RE, Jaffe BM, et al. The appendix. In: Brunicardi FC, Andersen DK, Billiar TR, ed. Schwartz's principles of surgery. New York: McGraw-Hill Companies 2005.

[11] Chandel V, Batt SH, Bhat MY, et al. Procalcitonin as the biomarker of inflammation in diagnosis of appendicitis in pediatric patients and prevention of unnecessary appendectomies. Indian J Surg 2011;73 (2):136-41.

[12] Kaya B, Sana B, Eris C, et al. The diagnostic value of Ddimer, procalcitonin and HS-CRP in acute appendicitis. Int J Med Sci 2012;9 (10):909-15.

[13] Jess P, Bjerregaard B, Brynitz S, et al. Acute appendicitis: prospective trial concerning diagnostic accuracy and complications. Am J Surg 1981;141 (2):232-4.

[14] Temple CL, Huchcroft SA, Temple WJ. The natural history of appendicitis in adults. A prospective study. Ann Surg 1995;221 (3):278-81.

[15] Kisacik B, Kalyoncu U, Erol MF, et al. Accurate diagnosis of acute abdomen in FMF and acute appendicitis patients: how can we use procalcitonin? Clin Rheumatol 2007;26 (12):2059-62.

[16] Sand M, Trullen X, Bechara F, et al. A prospective bicenter study investigating the diagnostic value of procalcitonin in patients with acute appendicitis. Eur Surg Res 2009;43 (3):291-7.

[17] Kafetzis D, Velissariou I, Nikolaides P, et al. Procalcitonin as a predictor of severe appendicitis in children. Eur J Clin Microbiol Infect Dis 2005;24 (7):484-7. 